\title{
DENSIDADE DE Neoseiulus californicus (MCGREGOR, 1954) (ACARI: PHYTOSEIIDAE) NO CONTROLE DO ÁCARO-VERMELHO DA MACIEIRA, FRAIBURGO-SC ${ }^{1}$
}

\author{
LINO BITTENCOURT MONTEIRO², AURELIE DOLL ${ }^{3}$, LUÍS FERNANDO BOEING $^{4}$
}

RESUMO- O controle biológico aplicado de Panonychus ulmi (Koch) (Acari: Tetranychidae) em macieira iniciou em Vacaria (RS), em 1992, com a multiplicação de Neoseiulus californicus em estufas e liberação nas áreas de ocorrência da praga, fazendo com que o equilíbrio entre ambos os ácaros ocorresse semanas após a liberação. O presente trabalho teve o objetivo de verificar o efeito da densidade de N. californicus a ser liberada em pomar de macieira, Malus domestica (Borkh.) Mansf., para o controle do ácarovermelho. Foi selecionado um pomar comercial em Fraiburgo (SC) e liberados os fitoseídeos nas densidades de 50.000, 100.000 e 150.000 por ha, originados da criação comercial situada na Renar Maçãs (Fraiburgo). O controle do ácaro foi medido através da injúria, devido à alimentação de $P$. ulmi, e avaliado por meio de uma escala de sintomas de bronzeamento, e do monitoramento de ovos hibernantes em maio, julho e setembro. O tratamento com 150.000 fitoseídeos reduziu a população de ácaros- vermelhos após 16 dias da liberação, enquanto os demais tratamentos necessitaram de 21 dias. A injúria das folhas foi menor no tratamento com 150.000. Os ovos hibernantes em maio, nas parcelas de 50.000 e 100.000, foram, respectivamente, $75 \%$ e $69 \%$ maiores do que na parcela com 150.000 fitoseídeos. Concluiu-se que a liberação de $150.000 \mathrm{~N}$. californicus foi mais eficiente no controle de $P$. ulmi no estágio fenológico reprodutivo da macieira.

Termos para indexação: Controle biológico, fitoseídeo, Panonychus ulmi, maçã.

\section{EFFECT OF Neoseiulus californicus MCGREGOR (ACARI: PHYTOSEIIDAE) DENSITY OF ON THE CONTROL OF RED MITE IN APPLE TREES}

\begin{abstract}
The applied biological control of Panonychus ulmi in apple orchards in Brazil began in Vacaria (RS), in 1992 by rearing Neoseiulus californicus in greenhouses and releasing them into infested areas. The balance between both mites took place weeks after the release. The aim of this work was to evaluate the effect of $N$. californicus density to be released in apple orchards for the control of the red mite. A commercial orchard in Fraiburgo (SC) was chosen and populations of 50,000, 100,000 and 150,000 phytoseiidae per ha were released. These populations were from the commercial breeding centre located at Renar Maçãs, in Fraiburgo. The damage, due to the feeding of $P$. ulmi was measured in terms of the range of brownish symptoms. The monitoring of hibernating eggs was carried out in May, July and September. The treatment with 150,000 phytoseiidae reduced the population of red mite 16 days after the release, while the other treatments required three weeks. The damage to the leaves was less in the treatment with 150,000 phytoseiidae. The monitoring of hibernating eggs using 50,000 and 100,000 phytoseiids/plot took place in May and it was 75\% and 69\% greater than in the plot using 150,000 phytoseiidae. It can be concluded that the release of 150,000 N. californicus was more efficient in the control of $P$. ulmi in the reproductive phenological stage of the apple tree.
\end{abstract}

Index terms: Biological control, phytoseiidae, Panonychus ulmi, apple.

\section{INTRODUÇÃO}

O controle biológico aplicado de ácaros foi adotado em várias culturas em países do Hemisfério Norte, incentivado por empresas que comercializam organismos para o controle de pragas, principalmente em ambientes protegidos, como os fitoseídeos Phytoseiulus persimilis (Athias-Henriot) e Amblyseius cucumeris (Oudemans).

No Brasil, o controle biológico do ácaro-vermelho da macieira (Malus domestica (Borkh.) Mansf.), Panonychus ulmi (Koch) (Acari: Tetranychidae), por meio de liberações massais do fitoseídeo Neoseiulus californicus (McGregor), foi testado pela primeira vez em Vacaria (RS), entre 1992 e 1996 (Monteiro, 1994, 2002a), e Fraiburgo (SC), a partir de 1995 (Monteiro, 2005). Para obtenção de milhares de fitoseídeos, foram construídas estufas de plástico $\left(256 \mathrm{~m}^{2}\right)$ e multiplicado Tetranychus urticae Koch (Acari: Tetranychidae) como presa (Monteiro, 2002b), sendo que atualmente existem três biofábricas em Santa Catarina e uma no Paraná.

A eficiência do controle do ácaro-vermelho, no primeiro ano de liberação, depende da época em que for liberado e da quantidade de fitoseídeos por hectare. Além do aspecto técnico, a densidade de fitoseídeos por hectare deve estar relacionada com os aspectos econômicos (Monteiro et al., 2006), entretanto

\footnotetext{
'(Trabalho 181-07). Recebido em: 30-07-2007. Aceito para publicação: 04-11-2007.

${ }^{2}$ Eng. Agr., prof., Dr. da Universidade Federal do Paraná. Rua dos Funcionários, 1540, caixa postal 19061, CEP 81.831- 990, Curitiba-PR E-mail: lbmonteiro@terra.com.br

${ }^{3}$ Eng. Agra . da Ecole Nationale Supérieure Agronomique de Rennes, França.

E-mail: aurelie.doll@wanadoo.fr

${ }^{4}$ Eng. Agrônomo da Renar Maças S.A., Fraiburgo-SC. E-mail: luiz@ renar.agr.br
}

Rev. Bras. Frutic., Jaboticabal - SP, v. 30, n. 4, p. 902-906 Dezembro 2008 
o custo e o benefício dependem de outros fatores, tais como: manejo de ervas invasoras, inseticidas para outras pragas, mãode-obra, etc.

O objetivo deste estudo foi determinar o efeito da densidade de liberação de $N$. californicus para o controle do ácaro-vermelho em pomar comercial em Fraiburgo-SC.

\section{MATERIAL E MÉTODOS}

Área de estudo. Um pomar de três ha de macieira 'Gala' com 13 anos de idade, plantada no espaçamento de 4,5 m entre linha e 1,5 m na linha de plantio, foi dividido em três parcelas, cada uma com seis linhas de macieira $\left(3.375 \mathrm{~m}^{2}\right)$. Nas duas linhas centrais, foram liberados $N$. californicus em todas as macieiras (166 plantas), a uma densidade equivalente a 50.000 (T 50), 100.000 (T 100) e 150.000 (T 150) por hectare. Foram selecionadas ao acaso 20 plantas nas duas linhas centrais para avaliação da eficiência de predação e danos do ácaro-vermelho sobre as folhas. Além da avaliação direta do fitoseídeo sobre a redução da população de $P$. ulmi no verão, foi avaliada a consequiência da predação em $P$. ulmi sobre o número de ovos hibernantes. A bordadura entre tratamentos foi constituída de quatro linhas de plantio entre cada parcela, além das duas filas periféricas de cada tratamento, constituindo-se $36 \mathrm{~m}$ de distância entre as linhas de observação.

Produção e liberação de Neoseiulus californicus. Os fitoseídeos utilizados para a liberação foram multiplicados na empresa Renar Maçãs, Fraiburgo (SC), em feijoeiro (Phaseolus vulgaris $\mathrm{L}$.), de acordo com a metodologia descrita por Monteiro (2002b). O número de fitoseídeos em cada tratamento foi definido por monitoramentos nas salas de criação antes da liberação, realizando a contagem de larvas, ninfas e adultos de fitoseídeos sobre todas as folhas dos feijoeiros contidas em 10 potes, excluindo ovos. A partir da média de três fitoseídeos por folha, os feijoeiros foram cortados e transferidos para o pomar, colocando-os homogeneamente sobre as macieiras, de modo que cada planta das duas linhas centrais recebesse, em média, 34 fitoseídeos para o tratamento T50; 68 fitoseídeos para T 100, e 102 para T 150. Folhas de feijoeiros com fitoseídeos foram cortadas pela metade, no momento em que foram distribuídas nas bases dos ramos do ano, com a finalidade de melhorar a distribuição dos $N$. californicus nas macieiras. A área de liberação ocorreu nas partes basal e mediana das macieiras, até 2,3 $\mathrm{m}$ de altura, sendo que o volume médio das macieiras foi de $5,6 \mathrm{~m}^{3}$; assim, cada planta dos tratamentos T 50, T 100 e T 150 recebeu cerca de, respectivamente, $6 ; 12$ e 18 fitoseídeos por $\mathrm{m}^{3}$ de macieira. A liberação de N. californicus ocorreu em 17 de fevereiro de 2004.

Monitoramento no verão. O monitoramento das populações de $N$. californicus e $P$. ulmi consistiu em coletar cinco folhas em cada uma das 20 macieiras marcadas por tratamento, situadas na altura de $1,7 \mathrm{~m}$ e desenvolvendo-se na parte mediana dos ramos de ano. As folhas foram colocadas em envelopes de papel e imediatamente acondicionadas em caixas de isopor com gelo para transporte ao Laboratório da Estação de Alerta de Fraiburgo. Foram contadas as formas jovens e adultas em cada folha com o auxílio de um estereomicroscópio (10x). O desenvolvimento de $P$. ulmi no ciclo vegetativo de 2004/2005 foi influenciado por fatores climáticos adversos em toda a região de Fraiburgo, de modo que os ácaros-vermelhos tiveram condições de desenvolverem-se sobre as folhas de macieiras em final de janeiro, o que justificou o início das liberações em 16-02-2004. O monitoramento de $P$. ulmi foi realizado aos $9 ; 16 ; 23$ e 30 dias após a liberação dos fitoseídeos, respectivamente: 25-02, 04-03, 11-03 e 18-03-2004.

Avaliação dos danos de $\boldsymbol{P}$. ulmi. Os sintomas de injúria provocados pela alimentação de $P$. ulmi nas folhas foram avaliados antes da liberação do fitoseídeo (15-02-2004) e nos dias de monitoramento, subsidiados por uma escala de bronzeamento (Monteiro, 2005). Essa escala tem sido utilizada nos últimos 10 anos para determinar a injúria das plantas e a necessidade de pulverização com acaricidas em pomares, em Fraiburgo, conduzidos com controle biológico. A avaliação do bronzeamento foi realizada nas folhas de quatro ramos do ano por planta, escolhidos aleatoriamente e desenvolvidos na parte mediana das 20 macieiras marcadas. A partir da avaliação nas folhas, definiu-se visualmente um valor médio de bronzeamento para cada uma das 20 plantas, seguindo a classe proposta na Tabela 1. Considerou-se que as folhas verdes pertencem à classe 1 , e as demais apresentam gradativamente um aumento de pontuações amarelas (sintoma de bronzeamento) devido à morte das células durante a alimentação do ácaro-vermelho. Essa escala de sintomas é qualitativa e foi utilizada neste estudo para definir a intensidade do ataque do ácaro-vermelho. O sintoma de bronzeamento foi avaliado nos dias 26-02, 04-03, 11-03 e 18-032004.

Ovos hibernantes de $P$. ulmi. A consequiência da estratégia de controle de $P$. ulmi no verão foi medida através da contagem de ovos hibernantes de $P$. ulmi ovipositados em torno das gemas desenvolvidas nos ramos de dois anos de idade (Baillod, 1979). Foram coletados três ramos retirados em cada uma das 20 macieiras selecionadas por tratamento, sendo que os ovos hibernantes foram contados em uma gema por ramo. As amostragens nas gemas ocorreram em 10 de maio, 15 de julho e $1^{\circ}$ de setembro. Os ovos remanescentes, avaliados em setembro, tiveram a influência tóxica do óleo mineral, visto que, para uniformizar a brotação da macieira, foi utilizado Dormex® ${ }^{\circledR}$ associado a 4\% de óleo mineral, em 20 de agosto.

Os resultados foram submetidos à análise de variância, comparando-se as médias pelo teste de Tukey, a 5\% de probabilidade. A população de ácaros e o número de ovos hibernantes foram comparados por análise de correlação de Pearson.

\section{RESULTADOS E DISCUSSÃO}

O levantamento realizado antes da liberação do fitoseídeo mostrou que as médias de ácaros-vermelhos sobre as folhas de macieira diferiram significativamente entre os tratamentos (Tabela 2), sendo que, no tratamento T 50, havia cerca de cinco ácaros a mais por folha do que nas demais parcelas. Entretanto, as folhas em todos os tratamentos apresentaram o sintoma de 
bronzeamento na classe 1 (Tabela 1). Em relação a $N$. californicus, as amostragens prévias das folhas não mostraram a presença do fitoseídeo em todos os tratamentos (Tabela 2).

A população de ácaro-vermelho no tratamento $\mathrm{T} 50$ foi significativamente maior em todo o período de avaliação, exceto aos 30 dias, alcançando o valor máximo aos 16 dias após a liberação de $N$. californicus (16 DAL), enquanto, nos outros tratamentos, o pico ocorreu sete dias antes, com menor número de fitófagos por folha (Tabela 2). A evolução populacional de $P$. ulmi no $\mathrm{T} 50$ pode ser explicada pela menor densidade de ácaros predadores (6 fitoseídeos $/ \mathrm{m}^{3}$ ) e pelo maior número de fitófagos por folha, no momento da liberação, em relação ao T 100 e T 150. Esses dois parâmetros, ocorrendo simultaneamente, são influenciados pelas condições abióticas em final de fevereiro, as quais são favoráveis ao crescimento da população de fitófagos (Monteiro, 2005), com atividade intensa de alimentação e repercutindo sobre o sintoma foliar.

A avaliação do bronzeamento aos 9 DAL mostrou que $75 \%$ das folhas se encontravam nas classes 3 e 4 no $\mathrm{T} 50$, enquanto, nos tratamentos T 100 e T 150 , foram observados, respectivamente, 40 e $30 \%$ de folhas nas mesmas classes (Figura 1). Entretanto, a correlação no $T 50$ entre o número de ácaros e folhas bronzeadas por classe é baixa $(\mathrm{R}=0,23 ; \mathrm{P}=0,31)$. Após 23 DAL (11-03), o número de folhas bronzeadas na classe 5 aumentou no $\mathrm{T} 50$, passando a possuir $75 \%$ das folhas nas classes 4 e $5(\mathrm{R}=0,44 ; \mathrm{P}=0,48)$, enquanto, para $\mathrm{T} 100$, foram observados $50 \%$ em ambas as classes. No T 150, ocorreram $35 \%$ das folhas bronzeadas correspondendo à classe 4 (Figura 1) e não houve sintomas de bronzeamento na classe 5, o que mostra que o tamanho da população de $P$. ulmi não foi capaz de proporcionar queda precoce de folhas (Tabela 1).

As observações das folhas quanto ao bronzeamento complementaram as informações quantitativas e, neste caso, mostraram que os ácaros-vermelhos causaram danos significativos às folhas das macieiras no $\mathrm{T} 50$, passando, em pouco mais de 30 dias, de tons amarelados para marrons (classe 5) em $45 \%$ das folhas, característica que assinala a queda precoce das mesmas. Mesmo com a redução de P. ulmi, as macieiras terão perda do potencial fotossintético com a queda precoce das folhas, armazenarão menos energia nas gemas e comprometerão o calibre e a produção no próximo ciclo (Kovaleski, 2004).

As amostragens realizadas aos $9 \mathrm{DAL}$, em todos os tratamentos, revelam que a relação entre o número de $N$. californicus liberado e o encontrado nas folhas foi baixa $(\mathrm{R}=$ 0,$29 ; \mathrm{F}=27,7 ; \mathrm{P}=0,00$ ), prevendo, entretanto, diferenças entre os tratamentos. A baixa correlação está associada às dificuldades de distribuição homogênea de $N$. californicus por meio de folhas de feijoeiro e pelas características de dispersão do gênero Neoseiulus (Coop \& Croft, 1995). O aumento do número de fitoseídeos ocorreu de forma desigual em cada tratamento, crescendo 2,3; 2,3 e 1,2 vezes entre 9 e 16 DAL, respectivamente, no T 50, T 100 e T 150 . O maior crescimento relativo de $N$. californicus, no T 50 e T 100, pode estar relacionado com a abundância de ácaros-vermelhos presentes até 16 DAL, quando houve a maior média de ácaros-vermelhos por folha. A abundância da presa no $\mathrm{T} 50$ teve repercussões positivas sobre o desenvolvimento de $N$. californicus em 23 e 30 DAL, quando ocorreu a maior densidade de fitoseídeos e redução do fitófago. Esse comportamento está associado às características de $N$. californicus, considerado como um fitoseídeo de limpeza, ou seja, multiplica-se rapidamente em presença abundante da presa, até a eliminação completa do fitófago (McMurtry e Croft, 1997). No T 100, a diminuição dos fitoseídeos, a partir de 23 DAL, coincide com a redução acentuada do fitófago observada na segunda amostragem após a liberação. O número de fitoseídeos por folha no T 150 permaneceu estável até 23 DAL, limitado pela baixa população de $P$. ulmi desde os $9 \mathrm{DAL}$, resultado similar ao obtido por Monteiro (2002a).

A densidade de liberação de $N$. californicus do T 150 proporcionou eficiente controle da população de $P$. ulmi desde o início das amostragens, minimizando o risco de haver folhas na classe 5 , sendo que $75 \%$ dessas se concentraram nas classes 1 a 3. Além disso, a eficiência de $N$. californicus tem repercussão na amostragem de ovos hibernantes do ácaro-vermelho.

A avaliação de ovos hibernantes realizada em maio/2004 mostrou que houve diferenças entre os tratamentos (Tabela 3), havendo uma tendência em ter maior número de ovos hibernantes nos tratamentos cujos ácaros-vermelhos se mantiveram por mais tempo em abundância sobre as folhas. As macieiras do T 150 tiveram menor número de ovos hibernantes $(\mathrm{F}=17,28 ; \mathrm{df}=2 ; \mathrm{P}>0,0)$ em relação aos demais, sendo que T 50 e T 100 não se diferenciaram entre si. Esse resultado sugere que a redução precoce de $P$. ulmi no T 150 influenciou no comportamento das fêmeas, seja pela redução numérica das fêmeas habilitadas à oviposição, seja pelos fatores abióticos não-favoráveis às posturas de inverno nesse momento, pois, normalmente, as posturas são feitas a partir do final de fevereiro, influenciadas pelo fotoperíodo, temperatura e condições nutritivas das folhas (Orth et al., 1986). Portanto, observou-se que houve correlação entre a população do ácaro-vermelho no $\mathrm{T} 150$, amostrada em 25 02-04 (9 DAL), e os ovos hibernantes avaliados em maio ( $\mathrm{F}=$ $19,48 ; \mathrm{df}=1 ; \mathrm{P}>0,0 ; \mathrm{R}=0,50)$. Em relação ao $\mathrm{T} 100$, houve correlação positiva $(\mathrm{R}=0,60)$ entre a população de $P$. ulmi, em 403-04 (16 DAL), e o número de ovos de maio $(\mathrm{F}=31,88 ; \mathrm{df}=1$; $\mathrm{P}>$ $0,0)$.

Duas outras avaliações em ovos hibernantes foram realizadas. Os resultados obtidos em julho mostram a mesma diferença significativa ocorrida em maio, observando-se, entretanto, redução superior a $80 \%$ de ovos hibernantes em todos os tratamentos. A redução pode ser em função da ação de $N$. californicus, embora não haja na literatura informações sobre o potencial de predação em ovos hibernantes.

Em setembro, as avaliações não mostraram nenhuma diferença entre os tratamentos, embora não se deva considerar um efeito do manejo realizado em fevereiro, pois, nessa época, parte da população de larvas deve ter eclodido, e os ovos remanescentes sofreram a ação asfixiante do óleo mineral (20 de agosto de 2004), que é normalmente utilizado anualmente para a quebra de dormência da macieira (Monteiro, 2002a). Em pomares onde o controle de $P$. ulmi é feito exclusivamente por acaricidas, observam-se valores acima de 20 ovos hibernantes por gema após a quebra de dormência (Monteiro, 2002a). 
Análise das posturas de ovos hibernantes de $P$. ulmi é uma metodologia eficaz para medir a eficiência da estratégia do controle biológico de ácaro-vermelho realizada no ciclo anterior, independentemente dos fatores bióticos e abióticos que influenciam sobre essas posturas.
A densidade de 150.000 N. californicus por hectare foi a mais eficiente no controle de $P$. ulmi no verão. A redução do ácaro-vermelho minimizou os sintomas de bronzeamento e queda precoce das folhas, em função da alimentação. O número de ovos hibernantes foi menor nesta densidade, nas avaliações ocorridas antes da quebra de dormência.

TABELA 1- Escala de injúria devido à alimentação de P. ulmi em folhas de macieira, área foliar com sintoma (bronzeamento) e risco de redução de produção de frutos no próximo ciclo vegetativo (Monteiro, 2005).

\begin{tabular}{lccl}
\hline $\begin{array}{l}\text { Classe de } \\
\text { injúria }\end{array}$ & $\begin{array}{c}\text { Área foliar } \\
\text { bronzeada }(\%)\end{array}$ & RAVCI $^{2}$ & \multicolumn{1}{c}{ Característica } \\
\hline 1 & $0-20$ & baixo & $\begin{array}{l}\text { Folhas verdes, mas com pontuações amareladas } \\
\text { parcialmente visíveis }\end{array}$ \\
2 & 40 & baixo & $\begin{array}{l}\text { Folhas com pontuações amareladas bem visíveis } \\
3\end{array}$ \\
4 & 60 & médio & Folhas verde-amareladas homogêneas \\
5 & 100 & alto & Folhas amareladas por inteiro \\
& alto & $\begin{array}{l}\text { Folhas totalmente amareladas e com manchas marrons } \\
\text { Pré-sintoma para a queda precoce de folhas }\end{array}$ \\
\hline
\end{tabular}

- baseado na \% de células mortas causada pela alimentação do ácaro-vermelho;

2. risco o ácaro-vermelho em causar injúrias (RAVCI) na planta e reduzir a produção no próximo ciclo vegetativo.

TABELA 2- Número médio de ácaros em folhas de macieira ( $\pm \mathrm{EP})$, antes e após a liberação de $N$. californicus em diferentes densidades. Fraiburgo, 16-02-2004 a 18-03-2004.

\begin{tabular}{|c|c|c|c|}
\hline \multirow{3}{*}{ Densidade de $N$. californicus } & \multicolumn{2}{|c|}{ Dias após a liberação / Número de ácaros } & \multirow{3}{*}{ Média geral } \\
\hline & P. ulmi & N. californicus & \\
\hline & \multicolumn{2}{|c|}{ antes da liberação } & \\
\hline 50.000 & $17,8 \pm 1,16 \mathrm{a}$ & $0,0 \pm 0,00 \mathrm{c}$ & 8,9 \\
\hline 100.000 & $12,7 \pm 1,14 b$ & $0,0 \pm 0,00 \mathrm{c}$ & 6,4 \\
\hline 150.000 & $12,2 \pm 1,38 \mathrm{~b}$ & $0,0 \pm 0,00 \mathrm{c}$ & 6,1 \\
\hline \multirow[t]{2}{*}{ Média } & 14,2 & $0,0 \pm$ & 7,1 \\
\hline & \multicolumn{2}{|c|}{9 dias } & \\
\hline 50.000 & $36,7 \pm 2,65 \mathrm{a}$ & $1,5 \pm 0,23 \mathrm{~d}$ & 19,1 \\
\hline 100.000 & $25,4 \pm 2,52 b$ & $2,7 \pm 0,31 \mathrm{~d}$ & 14,0 \\
\hline 150.000 & $16,9 \pm 2,00 \mathrm{c}$ & $3,9 \pm 0,40 \mathrm{~d}$ & 10,4 \\
\hline \multirow[t]{2}{*}{ Média } & 26,3 & 2,7 & 14,5 \\
\hline & \multicolumn{2}{|c|}{16 dias } & \\
\hline 50.000 & $62,1 \pm 4,42 \mathrm{a}$ & $3,5 \pm 0,38 \mathrm{c}$ & 32,8 \\
\hline 100.000 & $23,8 \pm 3,13 b$ & $6,1 \pm 0,49 \mathrm{c}$ & 15,0 \\
\hline 150.000 & $9,6 \pm 1,49 \mathrm{c}$ & $4,6 \pm 0,49 c$ & 7,1 \\
\hline \multirow[t]{2}{*}{ Média } & 31,8 & 4,8 & 18,3 \\
\hline & \multicolumn{2}{|c|}{23 dias } & \\
\hline 50.000 & $19,6 \pm 2,73 \mathrm{a}$ & $7,4 \pm 0,61 \mathrm{bc}$ & 13,5 \\
\hline 100.000 & $2,4 \pm 0,72 \mathrm{~cd}$ & $9,0 \pm 0,69 \mathrm{~b}$ & 5,7 \\
\hline 150.000 & $0,8 \pm 0,26 \mathrm{~d}$ & $6,9 \pm 0,66 \mathrm{bc}$ & 3,9 \\
\hline \multirow[t]{2}{*}{ Média } & 7,6 & 7,8 & 7,7 \\
\hline & \multicolumn{2}{|c|}{30 dias } & \\
\hline 50.000 & $0,56 \pm 0,19 d$ & $11,1 \pm 0,78 \mathrm{a}$ & 5,8 \\
\hline 100.000 & $0,0 \pm 0,02 \mathrm{~d}$ & $6,9 \pm 0,47 \mathrm{~b}$ & 3,5 \\
\hline 150.000 & $2,3 \pm 0,22 \mathrm{c}$ & $1,4 \pm 0,22 \mathrm{~cd}$ & 1,8 \\
\hline Média & 1,0 & 6,5 & 3,7 \\
\hline
\end{tabular}

Médias seguidas de mesma letra minúscula não diferem entre si, no dia de avaliação, em relação a ácaros e tratamento pelo teste Tukey $(\alpha=0,5)$. 
TABELA 3- Número de ovos hibernantes $( \pm$ EP) de $P$. ulmi em parcelas de macieira, avaliados em três períodos e com diferentes densidades de $N$. californicus, Fraiburgo, 2004.

\begin{tabular}{lccc}
\hline Densidade de $N$. & \multicolumn{3}{c}{ Mês de avaliação/ Número de ovos hibernantes } \\
\cline { 2 - 4 } californicus /ha & maio & julho & setembro \\
\hline 50.000 & $28,75 \pm 7,4 \mathrm{bB}$ & $5,5 \pm 2,8 \mathrm{aB}$ & $0,3 \pm 0,2 \mathrm{aA}$ \\
100.000 & $23,4 \pm 9,3 \mathrm{bB}$ & $3,2 \pm 1,2 \mathrm{aB}$ & $0,3 \pm 0,2 \mathrm{aA}$ \\
150.000 & $5,7 \pm 3,1 \mathrm{bA}$ & $0,7 \pm 0,5 \mathrm{aA}$ & $0,3 \pm 0,2 \mathrm{aA}$ \\
\hline
\end{tabular}

Médias seguidas de mesma letra minúscula não diferem entre si na linha, e maiúsculas não diferem entre si na coluna, pelo teste de Tukey $(\mathrm{p}<0,05)$. Valor do erro-padrão.
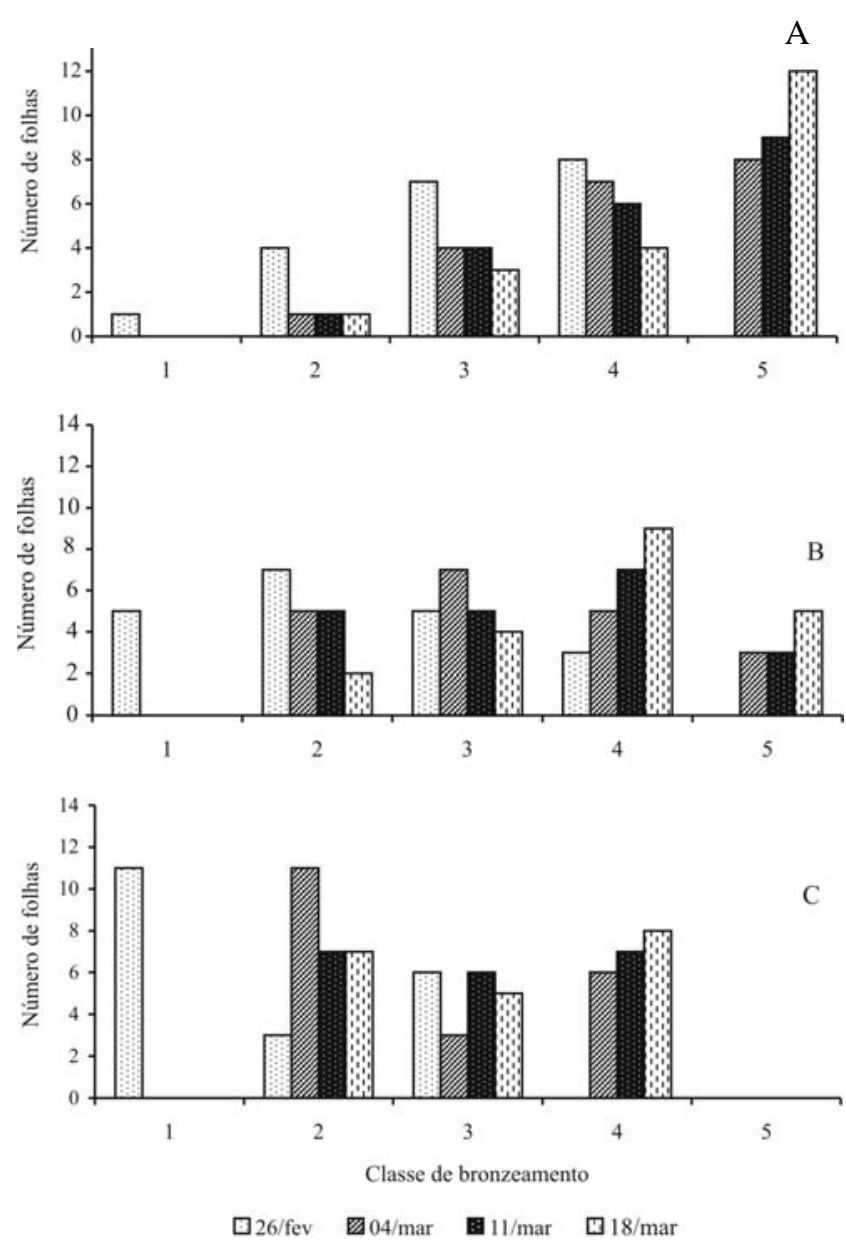

FIGURA 1- Evolução da injúria provocada pela alimentação de $P$. $u l m i$, em folhas de macieira, em função de cinco escalas de sintoma (bronzeamento), três densidades de $N$. californicus $(\mathrm{A}=50.000 ; \mathrm{B}=$ 100.000; $C=150.000)$ e quatro dias de avaliação. Fraiburgo, 2004.

\section{AGRADECIMENTOS}

À Renar Maçãs, pela cessão do pomar e auxílio na execução do experimento.

\section{REFERÊNCIAS}

BAILLOD, M. La technique et l'utilité du contrôle d'hiver des pontes de l'araignée rouge $(P$. ulmi) sur bois de taille en arboriculture fruitière. Revue Suisse Viticulture, Arboriculture e Horticulture, Nyon, v.11, p. 89-92, 1979.

COOP, L.B.; CROFT, B.A. Neoseiulus fallacis: dispersal and biological control of Tetranychus urticae following minimal inoculations into a strawberry field. Experimantal \& Applied Acarology, Amsterdam, v.19, p. 31-43, 1995.

KOVALESKI, A. Pragas. In: KOVALESKI, A. Maçã produção. Brasília: Embrapa, 2004. 169p.

MONTEIRO, L. B. Manejo integrado de Panonychus ulmi (Koch) (Acari: Tetranychidae) em macieira. Primeiras experiências com a introdução de Neoseiulus californicus (McGregor) (Acari: Phytoseiidae). Revista Brasileira de Fruticultura, Jaboticabal, v.6, p.46-53, 1994.

MONTEIRO, L.B. Manejo integrado de pragas em macieira no Rio Grande do Sul. Uso de Neoseiulus californicus McGregor (Acari: Phytoseiidae) para o controle de Panonychus ulmi Koch (Acari: Tetranychidae). Revista Brasileira de Fruticultura, Jaboticabal, v.23, p.395-405, 2002a.

MONTEIRO, L.B. Criação de ácaros fitófagos e predadores: um caso de produção de Neoseiulus californicus em produtores de maçã. In: PARRA, J.R.P; BOTELHO, P. S.M; CORREAFERREIRA, B.S.; BENTO, J.M.S. (Org.). Controle biológico no Brasil: parasitóides e predadores. São Paulo: Manole, 2002b. p.351-365.

MONTEIRO, L.B. Red apple tree mite management in Brazil using Neoseiulus californicus. A case of applied biological control. In: COLLOQUE INTERNATIONAL SUR LES ACARIENS DES CULTURES, 2., 2005. Montpellier. Paris. Anales... Paris: Association Française de Protection des Plantes, 2005 9p.

MONTEIRO, L. B.; A. SOUZA, A. PASTORI, P.L. Comparação econômica entre controle biológico e químico para o manejo do ácaro vermelho em macieira. Revista Brasileira de Fruticultura, Jaboticabal, v.28, p.514-517, 2006.

MCMURTRY, J.A.; CROFT, B.A. Life-styles of phytoseiid mites and their roles in biological control. Annual Review of Entomology, Palo Alto, v.42, p.291-321, 1997.

ORTH, A.I.; RIBEIRO, L.G.; REIS, W. Manejo de pragas. In. EMPASC. Manual da cultura da macieira. Florianópolis, 1986. $562 \mathrm{p}$. 